\title{
Sociobiology
}

RESEARCH ARTICLE - TERMITES

\section{Colony Breeding Structure of Reticulitermes (Isoptera: Rhinotermitidae) in Northwest Arkansas}

\author{
MA JANOWIECKI ${ }^{1}$, AD TRIPODI ${ }^{2,4}$, EL VARGO $^{1}$, AL SZALANSKI $^{3}$ \\ 1 - Department of Entomology, Texas A\&M University, College Station, Texas, USA \\ 2 - USDA ARS Pollinating Insect Research Unit, Logan, Utah, USA \\ 3 - Department of Entomology, University of Arkansas, Fayetteville, Arkansas, USA
}

\section{Article History}

Edited by

Paulo Cristaldo, UFRPE, Brazil

Received 21 February 2019

Initial acceptance 17 April 2019

Final acceptance 09 May 2019

Publication date 14 November 2019

\section{Keywords}

Termite, developed vs undeveloped, family structure, neotenics.

\section{Corresponding author \\ Allen Szalanski \\ University of Arkansas \\ AGRI 301C, Fayetteville, AR 72701. \\ E-Mail: aszalan@uark.edu}

\begin{abstract}
Termites, as social insects, have a complicated life cycle in which the colony breeding structure, that is the number of and origin of reproductives in a colony, can vary in relation to age and environmental factors. In this study, we used genetic methods to characterize the breeding structure of three species of Reticulitermes from three sites in northwest Arkansas and compared two habitats: undeveloped, forested sites and developed, agricultural sites. We found $57.1 \%$ of $R$. flavipes (Kollar) in northwest Arkansas $(n=28)$ were simple families, $39.3 \%$ were extended families and $3.6 \%$ were mixed families. Similarly, for $R$. hageni Banks ( $n=23$ ), we found $58.3 \%$ simple families, $33.3 \%$ extended families, and $8.3 \%$ mixed families. All of the $R$. virginicus (Banks) samples $(n=5)$ were simple families. For $R$. flavipes and $R$. hageni, the percentage of extended families is intermediate to southeastern and northern USA populations, corresponding to the intermediate seasonality and climate in Arkansas. The level of inbreeding in Arkansas, estimated via $F_{\mathrm{IT}}$, was relatively high and similar to northern populations of Reticulitermes. There were significantly more extended family colonies at the developed site compared to the two undeveloped sites which contained more simple family colonies. This difference may occur as a strategy to cope with sparse resources in urban environments or as a consequence of different abiotic factors.
\end{abstract}

\section{Introduction}

The complicated life style of termites prevents traditional research methods from adequately assessing aspects of their biology. Initially, a Reticulitermes (Isoptera; Rhinotermitidae) subterranean termite colony is founded by a monogamous pair of winged alates, forming a simple family. This pair can be replaced by secondary reproductive descended from the original founding pair, changing the breeding structure of the colony to an extended family (Vargo \& Husseneder, 2009). Less commonly, colonies can consist of cohabiting individuals from unrelated reproductives. These are referred to as mixed families, likely caused by colony fusion (Matsuura \& Nishida, 2001; Deheer \& Vargo, 2004; Fisher et al., 2004). While this structure is nearly impossible to determine from collecting and censusing colonies in the field, microsatellite DNA genotyping methods have been developed (Vargo 2000; Dronnet et al., 2004) and applied to Reticulitermes termites, primarily along the East Coast of the USA and Europe (Vargo \& Husseneder, 2009).

In $R$. flavipes (Kollar) populations examined in the southeastern USA, there are generally $75 \%$ simple families, $20 \%$ extended families, and $2 \%$ mixed families (Vargo \& Husseneder, 2009). In populations of $R$. flavipes further north in the USA (i.e. Virginia, Delaware, Massachusetts, Nebraska), there are more extended families (41.4-71.4\%) and higher levels of inbreeding that correlate to latitude and seasonal climatic variables (Ab Majid et al., 2013; Vargo et al., 2013). Breeding structure of $R$. hageni Banks and $R$. virginicus (Banks) have been determined in North and South Carolina and are primarily simple families $(>75 \%)$ with no mixed families (Vargo \& Husseneder, 2009). However, in 
$R$. virginicus this value may be elevated since this species undergoes asexual queen succession (AQS) (Vargo et al., 2012). In this system, female secondary reproductives are produced parthenogenetically, and therefore maintain the genetic structure of a simple family (Vargo et al., 2012). Microsatellite genotyping workers to determine the breeding structure of a colony often cannot differentiate between simple and extended families in AQS species.

Although many studies have investigated subterranean termites in either developed or undeveloped settings, few have compared aspects of termite biology between these two environments. In its invasive range in France, Dronnet et al. (2005) compared the genetic diversity of $R$. flavipes in urban and rural areas and found no differences. Similarly, family structure was not found to be different in urban compared to rural areas for Reticulitermes in the eastern USA (Vargo \& Husseneder, 2009). In Nebraska, there were more simple families of $R$. flavipes in developed sites compared to undeveloped sites that had more mixed families (Ab Majid et al., 2013; Ab Majid et al., 2018).

In Arkansas, three species of Reticulitermes occur: $R$. flavipes, R. hageni, and R. virginicus (Austin et al., 2004). These subterranean termites, especially $R$. flavipes, are economically important structural pests that cost Americans approximately $\$ 11$ billion annually for prevention, treatment, and repair of termite damage ( $\mathrm{Su}, 2002)$. In this study, we investigate family structure for these three species of Reticulitermes from three sites in northwest Arkansas. We also determined if there is a difference in family structure between developed and undeveloped areas.

\section{Materials and Methods}

Samples

Termites were collected from three sites in northwest Arkansas, USA (Fig 1): Lake Wedington unit of the Ozark St. Francis National Forest (OSFNF) (abbreviated: Lake Wedington) (36.13128, -94.3946), Lee Creek area of OSFNF (abbreviated: Lee Creek) (35.76183, -94.2738), and the University of Arkansas Agricultural Research and Extension Center, Fayetteville, AR (abbreviated: UARK Farm) (36.09908, -94.1659). Sites were separated by 17.7 to $35.4 \mathrm{~km}$ from one another. All samples were collected between July 2014 and Mar. 2016. Each sample represents a colony and multiple individuals were collected per colony. In northwest Arkansas, the mean annual temperature is $14.3{ }^{\circ} \mathrm{C}$ ranging from -4.5 to $32.1{ }^{\circ} \mathrm{C}$, and the average annual precipitation is $1180 \mathrm{~mm}$ (Fick \& Hijans, 2017).

Lake Wedington was created in the 1930s through the Northwest Arkansas Land Use Project that converted misused or idle farm land into recreational and national forest areas. From this location, 21 samples were collected from decaying logs (Table 1). Lee Creek is located south of Devil's Den State Park, in OSFNF. It is primarily secondary growth forest that was also developed in the 1930s through efforts of the Civilian Conservation Corps (Smith, 1992). Twenty-one samples were collected at this location (Table 1). The UARK Farm was established in 1888 under the Hatch Act of 1887, which provided research stations to Land Grant Universities (Strausberg, 1989; Hillison, 1996). It contains mainly secondary pine forests that separate buildings and experimental agricultural plots. Fourteen samples (Table 1) were collected from both decaying logs and Sentricon ${ }^{\circledR}$ Termite Colony Elimination System bait stations (Dow AgroSciences, Indianapolis, IN, USA) containing untreated pieces of pine wood. Fifty-six samples representing the three species and three localities were examined in this study (Table 1).

Table 1. Number of samples of each termite by location.

\begin{tabular}{lllll}
\hline Site & $R$. flavipes & $R$. hageni & $R$. virginicus & Total \\
\hline Lake Wedington & 10 & 10 & 1 & 21 \\
Lee Creek & 9 & 9 & 3 & 21 \\
UARK Farm & 9 & 4 & 1 & 14 \\
Totals & 28 & 23 & 5 & 56 \\
\hline
\end{tabular}

Land use per site was calculated in ArcGIS Desktop v.10.5.1 (Environmental Systems Research Institute (ESRI), Redlands, California, USA) using World_Imagery base maps (source: ESRI, DigitalGlobe, GeoEye, Earthstar Geographics, CNES/Airbus DS, USDA, USGA, AeroGRID, IGN, and the GIS User Community, last updated September 2018). A buffer circle with a radius of $500 \mathrm{~m}$ was drawn around each sample location. Within this area, different sections were manually drawn and scored as forest, water, road, agricultural, impervious surface, or building and the percentage of area was calculated for each (Fig 2 A-C). Each site was classified as "developed" or "undeveloped" according to the dominant $(>50 \%)$ land use within this radius. Areas that were dominated by heavily manipulated land uses (e.g., roads, impervious surface, buildings, or agriculture) were classified as developed, whereas areas dominated by forest were classified as undeveloped.

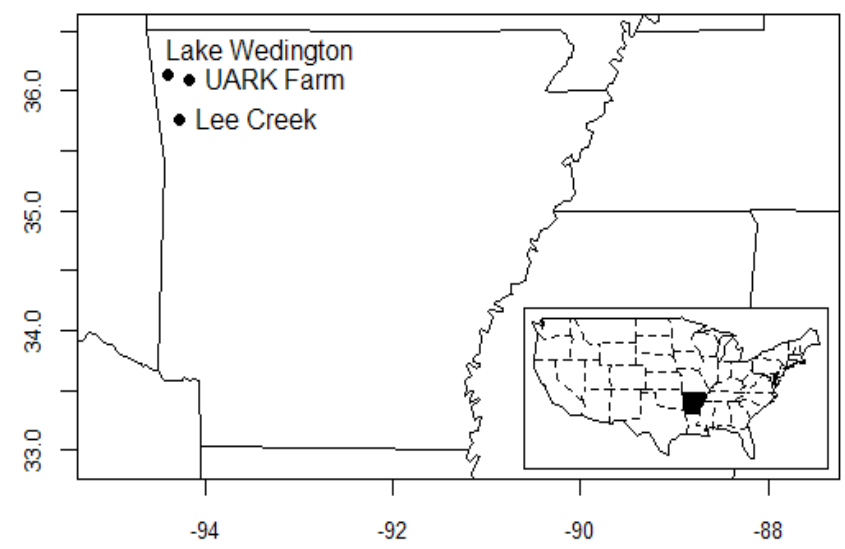

Fig 1. Sampling sites in northwest Arkansas, USA. 

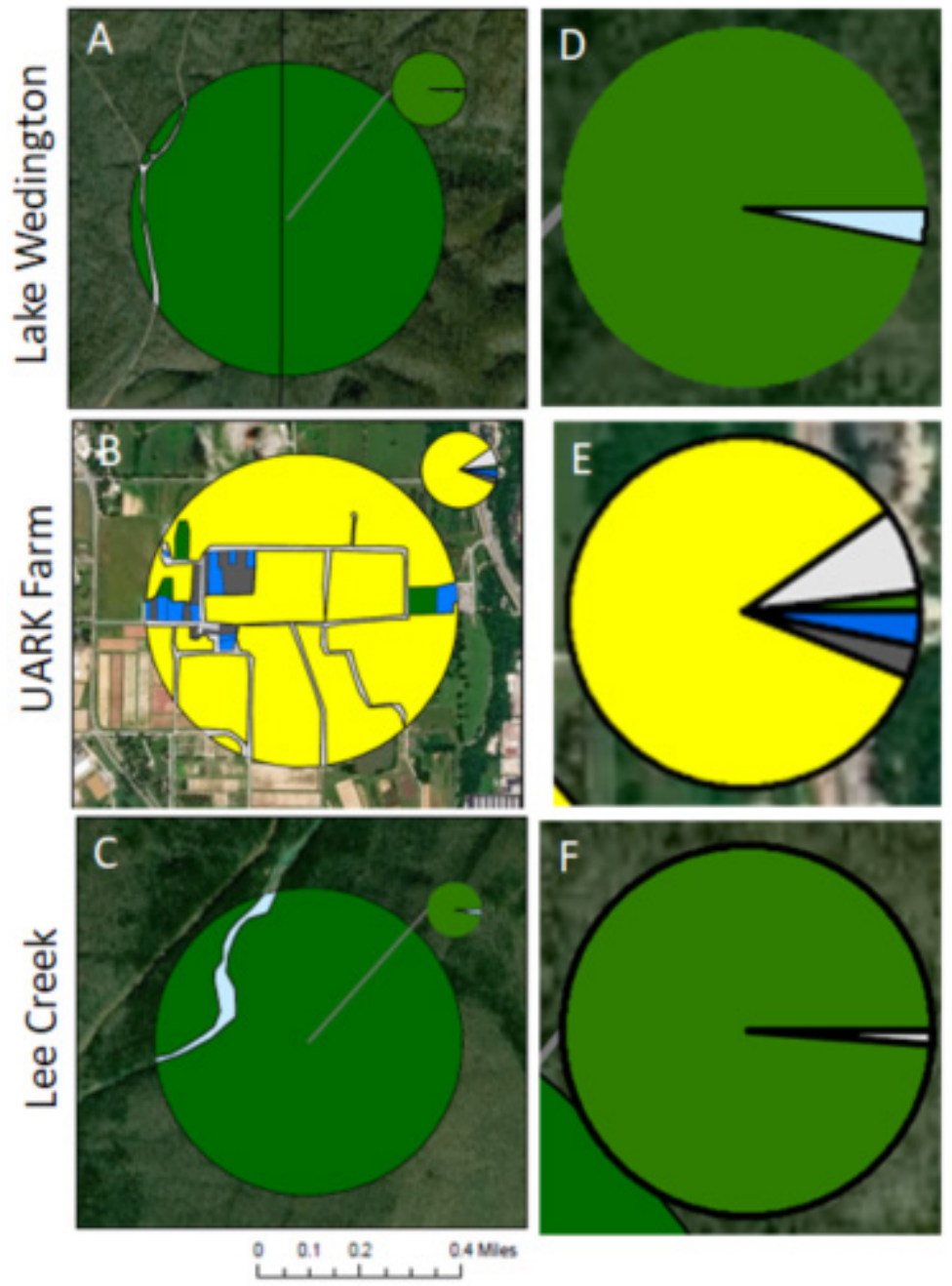

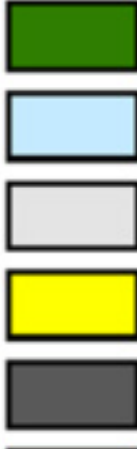

Forest

Water

Road

Agricultural

Impervious surface

Building

Fig 2. Land use for a circle with a $500 \mathrm{~m}$ radius around each sampling site in northwest Arkansas (A-C) summarized as a pie chart for each site (D-F).

All samples were collected into $95 \%$ ethanol and voucher specimens are deposited in the Texas A\&M University Insect Collection, College Station, TX, USA (\#740). Morphological identification, when possible, used the keys of Scheffrahn and $\mathrm{Su}$ (1994) and was confirmed genetically using PCR-RFLP (Szalanski et al., 2003) and DNA sequencing analysis using a region of the mtDNA 16S gene per Austin et al. (2004).

\section{Mitochondrial DNA Sequencing}

Genomic DNA was extracted from the head from an individual specimen using a salting-out procedure with inhouse reagents (Sambrook \& Russell, 2001). The 16S gene region of mtDNA was amplified using the primers $16 \mathrm{~S}$ : LR-J13007 (5'-TTACGCTGTTATCCCTAA-3') (Kambhampati \& Smith, 1995) and LR-N-13398 (5'-CGCCTGTTTATCAAA AACAT-3') (Simon et al., 1994). The PCR reagents followed Taylor et al. (1996) and the thermal cycler protocol consisted of 35 cycles of $94{ }^{\circ} \mathrm{C}$ for $45 \mathrm{~s}, 46{ }^{\circ} \mathrm{C}$ for $45 \mathrm{~s}$, and $71{ }^{\circ} \mathrm{C}$ for $60 \mathrm{~s}$. Samples were purified and concentrated with VWR centrifugal devices (VWR, Radnor, PA) and sent to Eurofins Genomics (Huntsville, AL) for direct sequencing in both directions. Consensus sequences were obtained from an alignment of sequences in both directions for each sample using Geneious v6.1.8 (Kearse et al., 2012). Haplotypes were determined by comparing to an in-house database (ALS, unpublished), and GenBank.

\section{Microsatellite Genotyping}

Genomic DNA was extracted individually from the heads of 20 worker termites from each sample using a saltingout procedure with in-house reagents (Sambrook \& Russell, 2001) and stored at $-20{ }^{\circ} \mathrm{C}$. Twelve total microsatellite loci (R. flavipes: 8 loci; R. hageni: 11 loci; $R$. virginicus: 7 loci) (Vargo, 2000; Dronnet et al., 2004) were amplified in a single multiplex of fluorescently-labeled primers (dye set: G5, Applied BioSystems, Life Technologies, Grand Island, NY, USA). Each species had a unique PCR reaction mix that can be found in Supplementary Tables 1-3. The thermal cycler condition (modified from: Vargo, 2000) consisted of a hot start at $95{ }^{\circ} \mathrm{C}$ followed by a touchdown program of six cycles at $94{ }^{\circ} \mathrm{C}(30 \mathrm{~s})$, $62{ }^{\circ} \mathrm{C}(30 \mathrm{~s})$, and $72{ }^{\circ} \mathrm{C}(30 \mathrm{~s})$ decreasing annealing temperature $1{ }^{\circ} \mathrm{C}$ per cycle; then 30 cycles of $94^{\circ} \mathrm{C}(30 \mathrm{~s}), 55^{\circ} \mathrm{C}(30 \mathrm{~s})$, and $72{ }^{\circ} \mathrm{C} \mathrm{(30s);} \mathrm{with} \mathrm{a} \mathrm{final} \mathrm{extension} \mathrm{at} 72{ }^{\circ} \mathrm{C}$ for $5 \mathrm{~min}$. Samples were genotyped at Iowa State University DNA Facility 
(Ames, IA, USA) using an ABI Prism 3730 DNA Analyzer (Applied Biosystems, Life Technologies, Grand Island, NY, USA) or in house with an ABI 3500 Genetic Analyzer (Applied Biosystems, Life Technologies, Grand Island, NY, USA) with GeneScan 500 LIZ dye size standard (Applied Biosystems, Life Technologies, Grand Island, NY, USA).

\section{Microsatellite Analysis}

Alleles were scored with the microsatellite plugin for Geneious v6.1.8 (Kearse et al., 2012). Individuals and loci with more than $50 \%$ missing data were removed from analysis. To access if all samples represented unique colonies, genotypic differentiation between samples were calculated with Genepop (Raymond \& Rousset, 1995). Following Vargo (2003), samples from unique colonies had pairwise genotypic differentiation values that were significantly $(p<0.05)$ different than zero, whereas samples of the same colony yielded nonsignificant $\mathrm{p}$-values. For any repeatedly sampled colony, only the first sample obtained was used for further analysis.

Within each colony, breeding structure was determined. Alleles per locus were calculated and used to distinguish mixed family structure. A mixed family, defined by Deheer and Vargo (2004), contain more than four alleles at any one locus, a characteristic only possible with a colony containing two or more unrelated reproductives. Remaining colonies that were not classified as mixed families were divided into simple and extended families based on whether they had genotypes consistent with a monogamous pair of reproductive, and if so, whether the genotype frequencies differed from the expected Mendelian ratios (Vargo, 2003). The genetic variation partitioning among the individual (I), colony (C), and total population $(\mathrm{T})$ were calculated in FSTAT v. 2.9.3 (Goudet, 2001) for each species separately. $F_{\text {IC }}$ and $F_{\text {IT }}$ estimate the level of inbreeding in individuals compared to others in the same colony and to others in the total population,

Table 2. 16S mtDNA haplotypes of each species by location.

\begin{tabular}{lccccc}
\hline 16S Haplotype & $\begin{array}{c}\text { Lake } \\
\text { Wedington }\end{array}$ & $\begin{array}{c}\text { Lee } \\
\text { Creek }\end{array}$ & $\begin{array}{c}\text { UARK } \\
\text { Farm }\end{array}$ & Total & $\begin{array}{c}\text { GenBank } \\
\text { accession } \\
\text { number }\end{array}$ \\
\hline R. flavipes GG/SS & 1 & 3 & 3 & 7 & AY702099 \\
R. flavipes J & 0 & 0 & 1 & 1 & AY441984 \\
R. flavipes M & 0 & 2 & 0 & 2 & AY441987 \\
R. flavipes MM & 1 & 0 & 1 & 2 & DQ001965 \\
R. flavipes P & 6 & 2 & 2 & 10 & AY538741 \\
R. flavipes R & 0 & 1 & 0 & 1 & AY603499 \\
R. flavipes TT & 2 & 1 & 2 & 5 & DQ001972 \\
R. hageni H1 & 7 & 8 & 2 & 17 & AY257235 \\
R. hageni H2 & 2 & 1 & 2 & 5 & AY603505 \\
R. hageni H4 & 1 & 0 & 0 & 1 & EU484333 \\
R. virginicus V1 & 1 & 2 & 0 & 3 & AY257241 \\
R. virginicus V15 & 0 & 1 & 1 & 2 & EU259775 \\
\hline
\end{tabular}

respectively (Vargo et al., 2013). $F_{\text {IC }}$ was calculated for the extended families only because it is useful in estimating the number of reproductives present (Vargo \& Husseneder, 2009). Differences in family structure by location were calculated with a Fisher exact probability test in R v. 3.4.1 (R Core Team 2013) because of the small sample size (i.e. more than $20 \%$ of cells are $\mathrm{n}<5$ ). Graphs were also generated in R v. 3.4.1 ( $\mathrm{R}$ Core Team 2013).

\section{Results}

\section{Species Identification}

For $R$. flavipes, there were seven unique 16S mtDNA haplotypes from the 28 samples. For $R$. hageni, there were three unique 16S haplotypes in the 23 samples. And for $R$. virginicus, there were two $16 \mathrm{~S}$ haplotypes in the 5 samples. Within a species, haplotypes were not exclusive to geographic location collected (Table 2).

\section{Family Structure}

A majority of pairwise genotypic differentiation values calculated for each species was significant, indicating that most samples represented unique colonies. To avoid sampling a single colony twice, eight samples with pairwise genotypic differentiation values close to zero were removed when comparing breeding structures between sites and species. Six of these samples were $R$. flavipes and two were $R$. virginicus. No samples of $R$. hageni were sampled twice. Combining all three species for the remaining samples $(\mathrm{n}=56)$, we observed $57.4 \%$ simple families, $37.7 \%$ extended families, and $4.9 \%$ mixed families (Fig 3, Table 3). All five colonies of $R$. virginicus collected were simple families. The $F_{\text {IC }}$ values for extended family colonies of $R$. flavipes (0.055) and $R$. hageni $(-0.082)$ were near zero, indicating that there were relatively high numbers of neotenics mating within the colony $(\sim 20$; Thorne et al., 1999). The relatively high values of $F_{\mathrm{IT}}$ for all three species indicate these colonies are inbred (Table 3).

\section{Family Structure by Site}

While there was no significant difference in the frequencies of different family types between sites for each species alone: $R$. flavipes (Fisher exact probability test, $\mathrm{p}=$ $0.0638, \mathrm{n}=28), R$. hageni $(\mathrm{p}=0.2679, \mathrm{n}=23), R$. virginicus $(\mathrm{p}=1.00, \mathrm{n}=5)$; there is a significant difference in family structure type by site for all species combined $(\mathrm{p}=0.012, \mathrm{n}$ $=56$ ). Generally, there were more extended families at the UARK Farm and more simple families at Lake Wedington and Lee Creek (Fig 3). There was no difference in family structure between Lake Wedington and Lee Creek for all three species combined $(\mathrm{p}=0.1575)$. Interestingly, all mixed families for $R$. flavipes and $R$. hageni occurred at one site: Lake Wedington (Fig 3). 
Table 3. Comparison of family structure types and inbreeding coefficients to other studies. Results from this study are shaded gray (modified from Vargo and Husseneder 2009, additional data from: Ab Majid et al. 2013, Perdereau et al. 2015, and Ab Majid et al. 2018).

\begin{tabular}{|c|c|c|c|c|c|}
\hline \multirow{2}{*}{ Species/Population $(\mathrm{N}=$ no. of colonies $)$} & \multirow{2}{*}{ Simple (Percent) } & \multicolumn{2}{|c|}{ Extended } & \multirow{2}{*}{$\begin{array}{l}\text { Mixed Families } \\
\text { (Percent) }\end{array}$} & \multirow{2}{*}{ Overall $F_{\mathrm{IT}}$} \\
\hline & & Percent & $F_{\text {IC }}$ & & \\
\hline \multicolumn{6}{|l|}{ Reticulitermes flavipes } \\
\hline Central North Carolina $(\mathrm{N}=319)$ & $78.4 \%$ & $19.7 \%$ & -0.209 & $1.9 \%$ & 0.052 \\
\hline Charleston, South Carolina $(\mathrm{N}=18)$ & $72.2 \%$ & $22.2 \%$ & -0.140 & $5.6 \%$ & 0.030 \\
\hline Eastern Massachusetts ( $\mathrm{N}=22)$ & $27.3 \%$ & $59.1 \%$ & 0.097 & $13.6 \%$ & 0.289 \\
\hline Lincoln, Nebraska $(\mathrm{N}=8)$ & $28.6 \%$ & $0 \%$ & NA* & $71.4 \%$ & 0.166 \\
\hline Nebraska (urban structures) $(\mathrm{N}=20)$ & $85.0 \%$ & $0 \%$ & NA & $15.0 \%$ & 0.111 \\
\hline Central Tennessee $(\mathrm{N}=48)$ & $\mathrm{NR} \dagger$ & NR & 0.260 & NR & 0.386 \\
\hline Northwest Arkansas $(\mathrm{N}=\mathbf{2 8})$ & $57.1 \%$ & $39.3 \%$ & 0.055 & $3.6 \%$ & 0.250 \\
\hline New Orleans, Louisiana $(\mathrm{N}=20)$ & $0 \%$ & $50 \%$ & 0.060 & $50 \%$ & 0.362 \\
\hline \multicolumn{6}{|l|}{ Reticulitermes hageni } \\
\hline Raleigh, North Carolina $(\mathrm{N}=15)$ & $86.7 \%$ & $13.3 \%$ & -0.257 & $0 \%$ & 0.357 \\
\hline Charleston, South Carolina $(\mathrm{N}=21)$ & $95.2 \%$ & $4.8 \%$ & NA & $0 \%$ & 0.140 \\
\hline Northwest Arkansas ( $\mathrm{N}=\mathbf{2 3}$ ) & $58.3 \%$ & $33.3 \%$ & -0.082 & $8.3 \%$ & 0.394 \\
\hline \multicolumn{6}{|l|}{ Reticulitermes virginicus } \\
\hline Raleigh, North Carolina $(\mathrm{N}=8)$ & $75 \%$ & $25 \%$ & -0.332 & $0 \%$ & 0.037 \\
\hline Charleston, South Carolina $(\mathrm{N}=4)$ & $100 \%$ & $0 \%$ & NA & $0 \%$ & -0.04 \\
\hline Northwest Arkansas ( $(\mathrm{N}=5)$ & $100.0 \%$ & $0.0 \%$ & NA & $0 \%$ & 0.241 \\
\hline
\end{tabular}

*not applicable, †not reported

\section{Discussion}

Variation in breeding structure has been observed in different species and populations although the cause of this variation is unclear (Vargo \& Husseneder, 2009). In R. flavipes, Vargo et al. (2013) found this variation in breeding structure and inbreeding was correlated to mean annual temperature and seasonality. In cool, moist habitats, there were higher levels of inbreeding and more extended families (Vargo et al., 2013). In Arkansas, our results align with this large-scale model but we also found differences in family structure between sites. This pattern of family structure aligns with the land use analysis where Lake Wedington and Lee Creek are undeveloped with mainly forest ( $>96 \%)$ whereas the UARK Farm is a developed site that has a wider variety of land use and is primarily agricultural land (>80\%) (Fig 2 D-F). In undeveloped, forested sites, there are more simple families compared to developed sites that have more extended families.

Across these three species of Reticulitermes in northwest Arkansas, only $57.4 \%$ of the colonies sampled were simple families, $37.7 \%$ were extended families, and $4.9 \%$ (2 samples) were mixed families (Fig 2, Table 3). Compared to previous studies, the percent of $R$. flavipes extended families is intermediate between southeastern (low percentage) and northern USA populations (high percentage) (Table 3) which corresponds to the intermediate seasonality in Arkansas (Vargo \& Husseneder, 2009; Vargo et al., 2013). For $R$. hageni, there are more extended families than was previously reported in North and South Carolina (Vargo \& Husseneder, 2009). In R. virginicus, the samples from northwest Arkansas are similar in family structure to South Carolina (Table 3) (Vargo \& Husseneder, 2009); although, this value may also be elevated because of the potential for asexual queen succession in this species (Vargo et al., 2012). Our methods may have been unable to distinguish between simple and extended families if parthenogenetic neotenics were present. For $R$. flavipes, the $F_{\text {IC }}$ value for extended families is positive but close to zero and similar to what was observed in Louisiana and Massachusetts indicating many neotenics reproducing in the colony. The $F_{\text {IT }}$ value estimated for $R$. flavipes in Arkansas is relatively high and similar to more populations in Tennessee and Massachusetts indicating a similarly high level of inbreeding. For $R$. hageni and $R$. virginicus, the $F_{\text {IT }}$ values are closer to the North Carolina values, which for $R$. virginicus are opposite of the family structure percentages that were more similar to South Carolina. 


\section{All Samples}

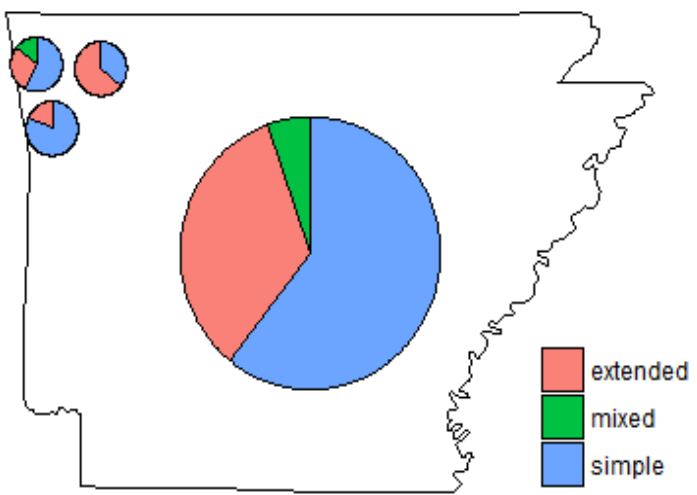

R. hageni

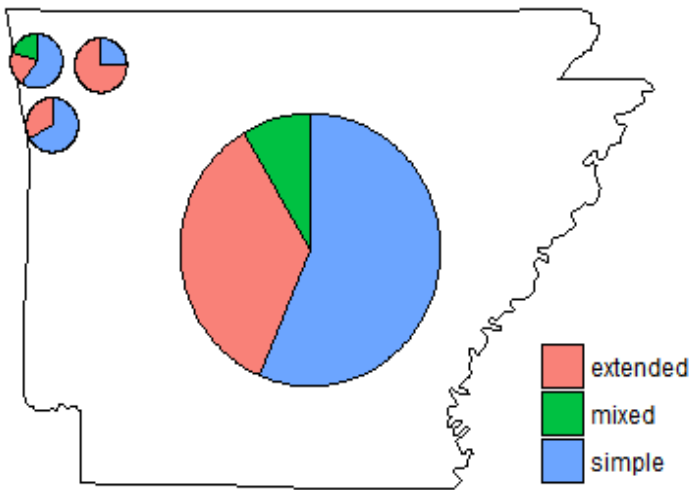

R. flavipes

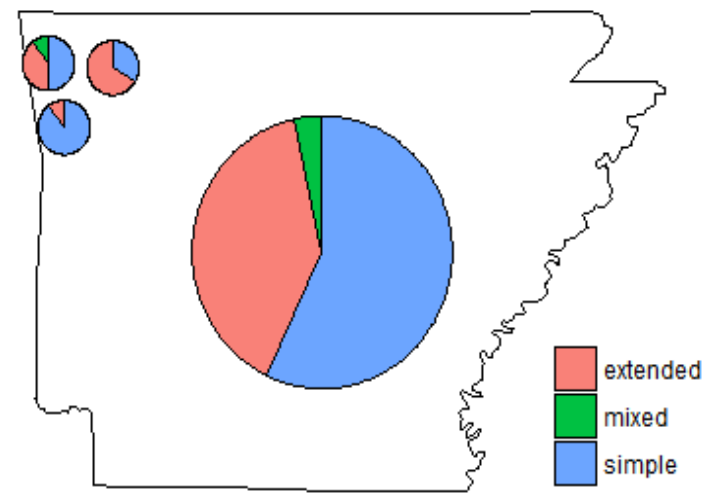

R. virginicus

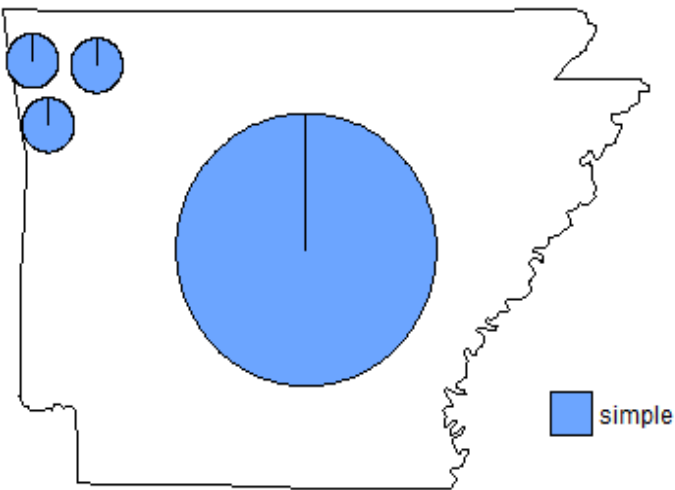

Fig 3. Family structure (simple, extended, or mixed family) comparison for the three different species (R. flavipes, $R$. hageni, and $R$. virginicus) and three different sampling locations in northwest Arkansas.

We found that the developed site, the UARK Farm, had relatively more extended family colonies of $R$. flavipes and $R$. hageni compared to the undeveloped sites (Fig 3) corresponding to differences in land use (Fig 2). This is the first report of this pattern of colonies of different family structure at developed vs. undeveloped sites. This stands in contrast to two studies in Nebraska on undeveloped (Ab Majid et al., 2013) and developed (Ab Majid et al., 2018) sites that found no extended families at either site but generally more simple families at developed sites compared to mixed families on undeveloped sites. However, this study of undeveloped sites in Nebraska represents a high outlier in the percent of mixed families (Table 3 ) and has a small sample size $(n=8)$.

As inferred from the genotypic differentiation, most samples represent unique colonies. There are several instances, however, where the same colony was sampled multiple times. Two samples collected from Sentricon ${ }^{\circledR}$ Termite Colony Elimination System bait stations within several meters of each other at the UARK Farm both sampled the same colony. Because they are near each other, this is not unexpected; however, it is interesting that only these two bait stations were foraged on by this colony, as there were multiple other bait stations in the same area that contained termites from different colonies. Two samples from Lee Creek in fallen logs also represent the same colony and were collected within several meters from each other. These are also understandably the same colony due to the close proximity of sampling. Overall, the basic spatial dynamics shown from these examples highlight an interesting aspect of termite biology that could be further investigated in future research to better understand how these species that appear to be inhabiting the same niche are able to coexist and partition space and resources.

Overall, we observed a relatively high percentage of extended families in northwest Arkansas. This is more than what has been observed in much of the eastern USA with the exception of northern populations. We further found a significant difference in family structure between our sampling sites that can be described by the land use with undeveloped, forested sites having more simple families and developed, agricultural sites having more extended families. This may reflect different strategies dependent on the abundance of resources. In the developed site there are less suitable resources to colonize compared to the undeveloped site, making inheriting the natal nest as an extended family potentially more profitable than attempting to found a new colony. Alternatively, this difference may be explained by adaptation to differences in temperature and moisture levels caused by urban heat islands or urban landscape management practices like irrigation, etc. 
These results highlight the importance of understanding how termite biology shifts as they invade urban habitats.

\section{Acknowledgements}

We wish to thank J. Austin, J. DeMark, and D. Johnson for providing samples. Also thanks to C. Trammel and C. Aguero for their technical support and assistance. We thank M. Ferguson and D. Shoemate for assistance with GIS analyses and anonymous referees for their comments. This research was supported in part by the University of Arkansas, Arkansas Agricultural Experiment Station and the Urban Entomology Endowment at Texas A\&M University.

\section{Authors Contribution}

MAJ, ALS, and ADT conceived and designed the project. MAJ collected the data. ADT, ELV, and MAJ conducted the data analysis. MAJ wrote the manuscript with support from ADT, ALS, and ELV.

\section{Supplementary Material}

http://periodicos.uefs.br/index.php/sociobiology/rt/ suppFiles/4376/0

http://dx.doi.org/10.13102/sociobiology.v66i3.4376.s2350

\section{References}

Ab Majid, A.H., S.T. Kamble, and N J. Miller. (2013). Colony genetic structure of Reticulitermes flavipes (Kollar) from natural populations in Nebraska. Journal of Entomological Science, 48: 222-233. doi: 10.18474/0749-8004-48.3.222

Ab Majid, A.H., S. Kamble, and H. Chen. (2018). Breeding patterns and population genetics of Eastern subterranean termites Reticulitermes flavipes in urban environment of Nebraska, United States. Sociobiology, 65: 506-514. doi: 10.13102/sociobiology.v65i3.2821

Austin, J.W., A.L. Szalanski, and M.T. Messenger. (2004). Mitochondrial DNA variation and distribution of the subterranean termite genus Reticulitermes (Isoptera: Rhinotermitidae) in Arkansas and Louisiana. Florida Entomologist, 87: 473-480.

Deheer, C.J., \& E.L. Vargo. (2004). Colony genetic organization and colony fusion in the termite Reticulitermes flavipes as revealed by foraging patterns over time and space. Molecular Ecology, 13: 431-441. doi: 10.1046/j.1365-294X.2003.2065.x

Dronnet, S., A.G. Bagnères, T. R. Juba, and E. L. Vargo. (2004). Polymorphic microsatellite loci in the European subterranean termite, Reticulitermes santonensis Feytaud. Molecular Ecology Notes, 4: 127-129. doi: 10.1111/j.14718286.2004.00600.x
Dronnet, S., M. Chapuisat, E.L. Vargo, C. Lohous, and A. G. Bagnères. (2005). Genetic analysis of the breeding system of an invasive subterranean termite, Reticulitermes santonensis, in urban and natural habitats.Molecular Ecology, 14: 13111320. doi: 10.1111/j.1365-294X.2005.02508.x

Fick, S.E. and R.J. Hijmans, 2017. Worldclim 2: New 1-km spatial resolution climate surfaces for global land areas. International Journal of Climatology, 37: 4302-4315.

Fisher, M.L., R.E. Gold, E.L. Vargo, and A.I. Cognato. (2004). Behavioral and genetic analysis of colony fusion in Reticulitermes flavipes (Isoptera: Rhinotermitidae). Sociobiology, 44: 564-576.

Goudet, J. (2001). FSTAT; a program to estimate and test gene diversities and fixation indices version 2.9.3. https:// www2.unil.ch/popgen/softwares/fstat.htm.

Hillison, J. (1996). The origins of agriscience: or where did all that scientific agriculture come from? Journal of Agricultural Education, 37: 8-13.

Kambhampati, S., and P. Smith. (1995). PCR primers for the amplification of four insect mitochondrial gene fragments. Insect Molecular Biology, 4: 233-236. doi: 10.1111/j.13652583.1995.tb00028.x

Kearse, M., R. Moir, A. Wilson, S. Stones-Havas, M. Cheung, S. Sturrock, S. Buxton, A. Cooper, S. Markowitz, C. Duran, T. Thierer, B. Ashton, P. Meintjes, and A. Drummond. (2012). Geneious Basic: An integrated and extendable desktop software platform for the organization and analysis of sequence data. Bioinformatics, 28: 1647-1649. doi: 10.1093/ bioinformatics/bts 199

Matsuura, K., and T. Nishida. (2001). Colony fusion in a termite: What makes the society "open"? Insectes Sociaux, 48: 378-383. doi: 10.1007/PL00001795

R Core Team. (2013). R: A language and environment for statistical computing. R Foundation for Statistical Computing, Vienna, Austria.

Raymond, M., and F. Rousset. (1995). GENEPOP (version 1.2): population genetics software for exact tests and ecumenicism. Journal of Heredity, 86: 248-249.

Sambrook, J., and D. W. Russell. (2001). Molecular cloning: A laboratory manual. Cold Spring Harbor, NY: Cold Spring Harbor Laboratory Press, 2028 p.

Scheffrahn, R. H., and N.-Y. Su. (1994). Keys to soldier and winged adult termites (Isoptera) of Florida. Florida Entomologist, 77: 460-474. doi: 10.2307/3495700

Simon, C., F. Frati, A. Beckenbach, B. Crespi, H. Liu, and P. Flook. (1994). Evolution, weighting \& phylogenetic utility of mitochondrial sequences and a compilation of conserved polymerase chain reaction primers. Annuals of the Entomological Society of America, 87: 651-701. doi: 10.1093/aesa/87.6.651 
Smith, S.T. (1992). The Civilian Conservation Corps in Arkansas, 1933-1942. Little Rock, AR: Arkansas Historic Preservation Program, $19 \mathrm{p}$.

Strausberg, S.F. (1989). A Century of research: Centennial history of the Arkansas Agricultural Experiment Station. Fayetteville, AR: Arkansas Agricultural Experiment Station, $207 \mathrm{p}$.

Su, N.-Y. (2002). Novel technologies for subterranean termite control. Sociobiology, 40: 95-101.

Szalanski, A.L., J.W. Austin, and C.B. Owens. (2003). Identification of Reticulitermes spp. (Isoptera: Reticulitermatidae [sic] Rhinotermatidae) from south central United States by PCR-RFLP. Journal of Economic Entomology, 96: 15141519. doi: $10.1093 /$ jee/96.5.1514

Taylor, D.B., A.L. Szalanski, and R.D. PETERSON. (1996). Identification of screwworm species by polymerase chain reaction-restriction fragment length polymorphism. Medical and Veterinary Entomology, 10: 63-70. doi: 10.1111/j.13652915.1996.tb00083.x

Thorne, B. L., J. F. A. Traniello, E. S. Adams, and M. Bulmer. (1999). Reproductive dynamics and colony structure of subterranean termites of the genus Reticulitermes (Isoptera Rhinotermitidae): A review of the evidence from behavioral, ecological, and genetic studies. Ethology, Ecology and Evolution, 11:149-169. doi: 10.1080/08927014.1999.9522833

Vargo, E. L. (2000). Polymorphism at trinucleotide microsatellite loci in the subterranean termite Reticulitermes flavipes. Molecular Ecology, 9: 817-829. doi: 10.1046/j.1365-294x.2000.00915.x

Vargo, E. L. (2003). Genetic structure of Reticulitermes flavipes and $R$. virginicus (Isoptera: Rhinotermitidae) colonies in an urban habitat and tracking of colonies following treatment with hexaflumuron bait. Environmental Entomology, 32: 12711282. doi: $10.1603 / 0046-225 \mathrm{X}-32.5 .1271$

Vargo, E.L., and C. Husseneder. (2009). Biology of subterranean termites: insights from molecular studies of Reticulitermes and Coptotermes. Annual Review of Entomology, 54: 379-403. doi: 10.1146/annurev.ento.54.110807.090443

Vargo, E. L., P. E. Labadie, and K. Matsuura. (2012). Asexual queen succession in the subterranean termite Reticulitermes virginicus. Proceedings of the Royal Society B Biological Sciences, 279: 813-819. doi: 10.1098/rspb.2011.1030

Vargo, E.L., L. Leniaud, L.E. Swoboda, S.E. Diamond, M.D. Weiser, D.M. Miller, and A.G. Bagnères. (2013). Clinal variation in colony breeding structure and level of inbreeding in the subterranean termites Reticulitermes flavipes and R. grassei. Molecular Ecology, 22: 1447-1462. doi: 10.1111/mec.12166

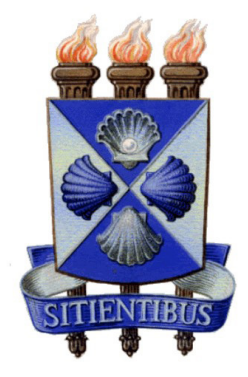

